\title{
Future Development Through the Past: Pathology of the Financing Dimension of Iran's Health Transformation Plan
}

This article was published in the following Dove Press journal:

ClinicoEconomics and Outcomes Research

\section{Leila Doshmangir (D) ${ }^{1-3}$ \\ Behzad Najafi (ID) \\ Hakimeh Mostafavi ${ }^{4}$ \\ Esmaeil Moshiri (D) ${ }^{5}$}

'Tabriz Health Services Management Research Center, Iranian Center of Excellence in Health Management, School of Management and Medical Informatics, Tabriz University of Medical Sciences, Tabriz, Iran; ${ }^{2}$ Social Determinants of Health Research Canter, Health Management and Safety Promotion Research Institute, Tabriz University of Medical Sciences, Tabriz, Iran; ${ }^{3}$ Department of Health Policy and Management, School of Management and Medical Informatics, Tabriz University of Medical Sciences, Tabriz, Iran; ${ }^{4}$ Health Economy, Standard and Health Technology Office, Shahid Beheshti University of Medical Sciences, Tehran, Iran; ${ }^{5}$ Social Determinants of Health Research Center, Semnan University of Medical Sciences, Semnan, Iran
Correspondence: Leila Doshmangir Email Doshmangirl@tbzmed.ac.ir
Background: In Iran, during the years, the budgeting model used for healthcare funding is affected by factors such as global oil prices and fluctuation in the exchange rates. So, developing or continuing to implement a plan in the health system depends on the current and future global and local economic trends.

Objective: To analyze the future of the recent significant reform called Health Transformation Plan (HTP), started on June 15, 2014, in the light of potential financial barriers and challenges.

Methods: Face-to-face interviews were conducted with health policymakers at different levels of the health system, health researchers, health insurance officers, and faculty members. Also, published and unpublished documents about HTP in the country and worldwide were reviewed. Data analysis was done using a qualitative inductive content analysis approach and assisted by qualitative data management software.

Results: Instability of financial resources and allocation of gross domestic product (GDP) to the HTP in the traditional way is a challenge in continuing this policy reform. Also, the bureaucratic procedures in allocation and distribution of funds, the discrepancy between health insurance funds and affiliated units of Ministry of Health and Medical Education (MoHME) especially Medical Sciences Universities (MSU), the lack of purchaser-provider split, inappropriate payments and compensation mechanisms, and dependence of MSU on especial revenues are the main challenges that threaten the future of HTP in Iran.

Conclusion: Given the current situation, where the country's funding resources are often unpredictable, it seems that such funding challenges will lead to poor HTP results. Therefore, the continuance of such a high cost-based plan requires the strategies and policies to ensure raising additional funds through various types of innovative financing to overcome challenges.

Keywords: Health Transformation Plan, health system, health policy, financing

\section{Introduction}

Financing is one of the main functions of the health system. ${ }^{1,2}$ Financial resources are an essential component of health systems, but they cannot potentially produce effective, efficient, and fair health care. ${ }^{1}$ Spending more on health and injecting more funds does not necessarily mean better health outcomes. ${ }^{3}$ Achieving health outcomes following the goals of the health system requires the use of appropriate financing methods and policies and also ensuring sustainability. ${ }^{4,5}$ Allocating a share of GDP to health expenditure and comparing their health outcomes, 
confirmed it properly in some countries in Eastern Mediterranean regions and other countries. ${ }^{6-8}$ Modifying the method of health-care provision and resource allocation is one of the most important and controversial policy decisions in health systems globally. ${ }^{9}$ The World Health Organization has asserted that moving to universal health coverage (UHC) is impeded by three fundamental interrelated problems that are all rooted in financing constraints: the unavailability of resources, an overreliance on direct payments, and inefficient and inequitable use of resources. 4

During the past decades, the Iranian health system has implemented several policy plans such as the Primary Health Care (PHC) network (1985), ${ }^{10}$ National Health Insurance coverage program, ${ }^{11}$ and rural family physician program (2004) ${ }^{12}$ to improve health status and achieve UHC. These resulted in the improvement of some health outcomes like life expectancy at birth, and mother and child morbidity and mortality rates. ${ }^{12,13}$ Along with other challenges to implementing and continuing the policy reforms, the financing dimension of the reforms has also been a pivotal and challenging issue.

\section{Health Transformation Plan in Iran: Aims, Process, and Outcomes}

On June 15, 2014, with changes in the political space after the presidential election, an appropriate opportunity was provided for the Ministry of Health and Medical Education (MoHME) to set a policy agenda and formulate a new reform called Health Transformation Plan (HTP) in Iran. ${ }^{12}$ HTP was implemented in an environment of the highest level of political propaganda and advertisements. ${ }^{14}$ The HTP was a showcase of government services and was heavily supported by the government and the President himself. In fact, political commitment led to a strong beginning to HTP implementation.

The primary goals of the health transformation plan involved four consecutive steps, ie, "improving access, affordability, and quality of care," "self-care development," "changing medical tariffs," and "transforming medical education."14

Iranian HTP was developed intending to ensure and enhance health-care accessibility, financial protection, and equity by developing strategies for revenue raising and reduction in Out-of-Pocket payments (OOP). ${ }^{14,15}$ In the first year, the plan achieved some goals and enhanced people's satisfaction. ${ }^{16}$ Analyzing the effects of this plan indicates some appropriate effects such as promoting access to health services, increasing patient satisfaction, improving the quality of hospital hoteling services in public hospitals, creating an appropriate health insurance coverage, managing the pharmaceutical market, especially medical supplies, reduction in OOP in inpatient care at public hospitals, and increased numbers of natural childbirth instead of cesarean section. However, in spite of the significant reduction in OOP, ${ }^{14,17}$ the impact of HTP on financial protection indicators like catastrophic health expenditure and impoverishment is controversial. ${ }^{17-19}$ On the other hand, total health expenditure rose more than the past, and ${ }^{14,17}$ economic circumstances led to a decrease in government revenue. This situation affected the HTP and allocation of resources to the plan, and also intensified financing challenges of HTP.

Some months after the implementation of the HTP plan, some other challenges, especially in terms of funding, including increase in supplier-induced demand in health care, a sharp increase of health expenditure, higher dissatisfaction of providers due to irrational medical tariffs and unfair payments, more disruptions in the drug supply chain, and uncertainty in funding sources, caused worries about continuing implementation of this plan according to the predefined way. ${ }^{20}$

Achieving the goals and objectives outlined in the HTP plan requires adequate approaches, and health policymakers and planners have asserted the introduction of successful corrective measures to address the financial obstacles to promote the continuation of this program and to achieve its goals. Therefore, we planned this study with the aim to investigate and analyze the financing dimension of HTP in Iran as an essential step to inform on the successes and failures, and to provide some suggestions to plan for formulating and implementing evidenceinformed policy interventions in the future.

\section{Context: Health Financing System in Iran}

In Iran, health-care financing is mainly based on social insurance and is a mixed funding system. The health system is financed from four main sources: tax revenue, oil revenue, OOP, and premium. Since implementing HTP, two more sources (value added tax (VAT) and subsidy targeting revenue) were added, and health funds increased dramatically. ${ }^{14}$ In the first months of implementation of HTP, the income from VAT and subsidy targeting revenue was allocated to MoHME directly. MoHME assigns this 


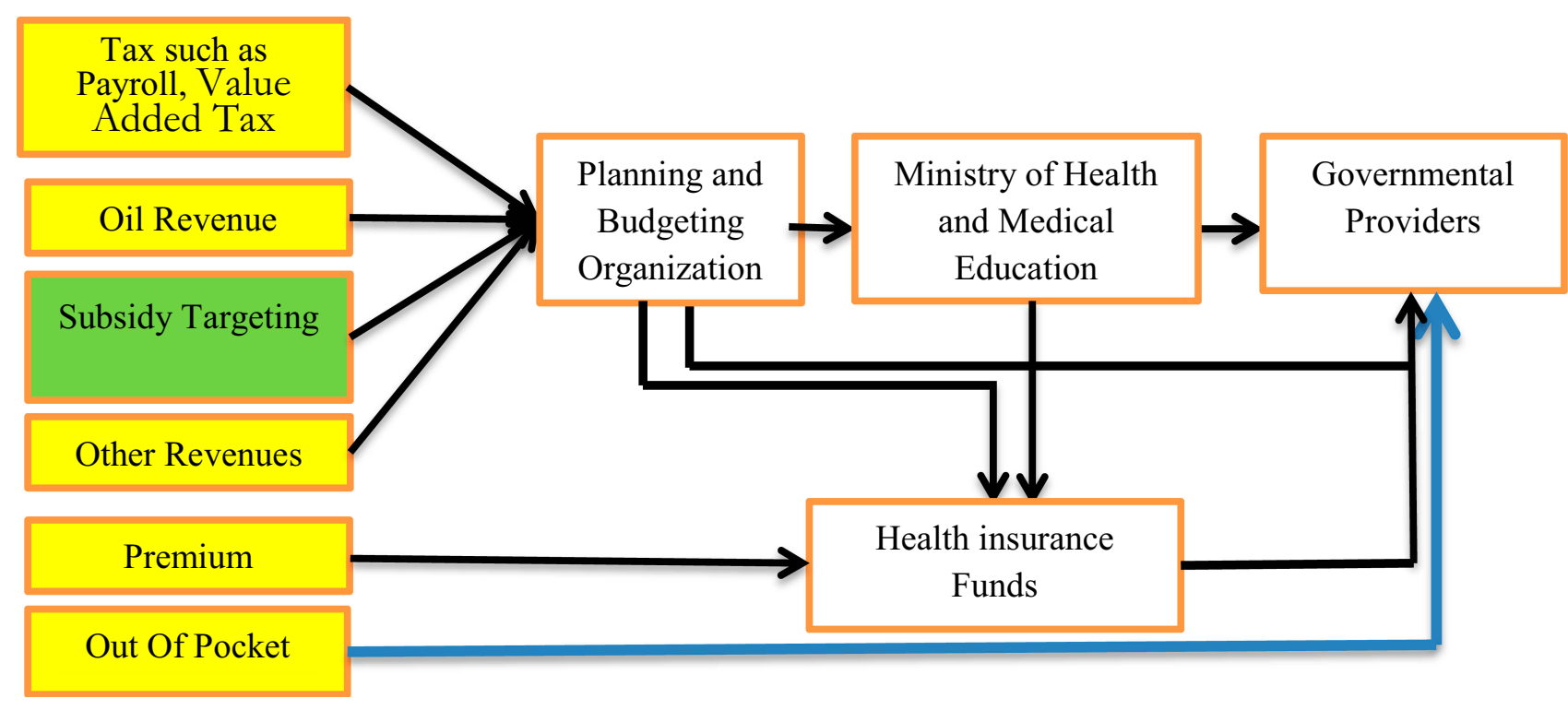

Figure I Flow of funds in the governmental sector.

allocated income to its own providers and health insurance organizations (Figure 1).

The Planning and Budgeting Organization (PBO) of the country in close collaboration with the financial department of MoHME has the leading role in determining the size of the health budget. After approving the budget by the cabinet and the parliament, the determined budget is allocated to the health system. ${ }^{21}$ Iran has four main public health insurance organizations: Social Security Organization (SSO), which is one of the largest health insurance organizations in the country, Iran Health Insurance Organization (IHIO), the Armed Forces Medical Services Insurance Organization (AFMSIO), and Imam Khomeini Relief Foundation Health Insurance (IKRF). ${ }^{22}$ All of these basic insurance organizations benefit from government support at various levels. $^{23}$ The SSO (established in 1975) is a nongovernmental organization and provides health insurance coverage for those officially employed in the private sector and their dependents, as well as self-employed persons via additional voluntary insurance. ${ }^{24,25}$ The IHIO (established in 1994 and previously known as the Medical Services Insurance Organization) provides health insurance for government employees and their dependents, rural residents, and other population categories (ie, students, specific professional associations, self-employed and their dependents). ${ }^{26}$ Currently, more than $90 \%$ of the insured population is being covered by the SSO and the IHIO. The AFMSIO (established in 1974) provides health insurance for military personnel and their families. The IKRF (established in 1994 following the establishment of the IHIO) provides health insurance coverage for the poor. In addition to four basic insurance funds, there are another 17 smaller institutional funds that provide health insurance coverage for their employees. ${ }^{22,27}$

The payment mechanism is also mixed in Iran. Budgeting, salary, case base payment, capitation, and the Fee For Services (FFS) mechanism are applied for payment and reimbursement. IR Iran has spent 144 billion international dollars ( 1 international dollar $=9044$ IRI Rials) for health in 2017.

\section{Methods and Materials}

In our study, we selected qualitative research in order to explore the future of the HTP from the lens of planners of the plan and other stakeholders. The qualitative study is most commonly used to help inform new concepts, hypotheses, and products. $^{28}$ In the study, we aimed to unearth the opinions, thoughts, and feelings of respondents regarding the respected subject. The data collection and analysis were conducted from August 2015 to October 2018.

Data were collected using a combination of reviews of relevant published and unpublished documents, and interviews with the health system's key informants. We included related national reports, acts, bylaws, regulations, governmental-approved rules, and related research projects. The documents were carefully selected based on Jupp's four considerations including originality, validity (accuracy), being the representative of related documents, 
and meaning (what is said) ${ }^{29}$ One of the researchers (LD) authenticated the findings from the document analysis following the inductive process.

Semi-structured interviews with 21 key informants have been conducted through purposeful and snowball sampling techniques (Table 1 shows the interviewees' characteristics). With one exception all interviews were conducted in person, and had a semi-structured open-ended format (Figure S1 shows the interview guide). We selected two criteria to recruit informants who had expertise in the subject area and also had experience in the policy-making process of the reform. Before the interviews, we called the participants and asked them to participate in the study and we got their positive answer for participation in the study. Each interview lasted between 40 and $80 \mathrm{~min}$. All interviews were audiorecorded and transcribed verbatim.

One member of the research team (LD) was responsible for conducting the face-to-face interviews, and she received verbal informed consent from all informants. Interviews were recorded digitally and then transcribed verbatim. Due to difficulties with interpreting one interview, another interview was scheduled with the same person to adjust the interpretation. An initial analysis of the transcript was conducted after the first interview. To ensure the validity and reliability of findings, we used all perspectives of research team members in coding and analyzing both interview transcripts and documents. Results were sent to the interviewees and feedback was requested about the accuracy of the content. This ensured that the researchers and the informants are viewing the data consistently. Appropriate samples were selected to increase the transferability of findings and the results were obtained and analyzed simultaneously. A qualitative inductive content analysis approach was undertaken ${ }^{30,31}$ and assisted by qualitative data management software MAXQDA 12. To conduct the analysis, two members of the research team (L.D. \& H.M.), through a repeated reading process, studied all transcribed interviews and documents, and then the researchers transcribed notes and headings onto a coding sheet. In the next step, they grouped the data, reducing the number of categories by combining similar headings into broader categories. In the final step, through repeated examination and comparison, themes emerged.

\section{Results}

We categorized the finding in four main themes: revenue raising, purchasing and resource allocation, payment mechanism, and the pooling management. The details are presented below.

\section{Revenue Raising}

Raising revenue plays an important role in developing a program or designing a reform in the health sector. To implement the reform, two sources including value-added tax (VAT) and subsidy targeting revenue were added to the current financing sources of the health system. After starting the reform, some concerns were raised in continuing this big reform.

The main revenues for HTP are the revenue which releases from subsidy targeting plan (10\% of total revenue) and 1 of $9 \%$ value-added tax [Senior insurance policy maker].

Table I Characteristics of Study Participants

\begin{tabular}{|c|c|c|c|c|}
\hline Number & Organization & Position & $\begin{array}{l}\text { Years of } \\
\text { Experience }\end{array}$ & $\begin{array}{l}\text { Number of } \\
\text { participants }\end{array}$ \\
\hline I & MoHME & Senior national officials, senior policy officials & $10-22$ & 4 \\
\hline 2 & Parliament & $\begin{array}{l}\text { Senior policy officials in the health commission of } \\
\text { parliament }\end{array}$ & 12 and 19 & 2 \\
\hline 3 & $\begin{array}{l}\text { Insurance } \\
\text { organizations }\end{array}$ & National and provincial insurance policy makers & $8-18$ & 3 \\
\hline 4 & $\begin{array}{l}\text { Health research } \\
\text { centers }\end{array}$ & Senior research professors & $4-25$ & 3 \\
\hline 5 & Medical universities & Faculty member & $3-27$ & 3 \\
\hline 6 & Hospitals & Hospital manager & $18-26$ & 3 \\
\hline \multirow[t]{2}{*}{7} & Others & $\mathrm{PhD}$ students in health policy, health economic & $2-4$ & 2 \\
\hline & & Independent health policy researcher & 35 & I \\
\hline Total & & & & 21 \\
\hline
\end{tabular}


It seemed the revenue from these sources is sufficient for running the plan. After one year of the beginning of the plan, it was encountered with some problems, and challenges and animadversions were started. [Senior health official]

According to the participants, one of the main criticisms was the unsustainability of funding sources, as well as the lack of appropriate projection of the financial burden of HTP specifically on the other counterparts and beneficiaries like health insurance organizations.

Revenues had been predicted just for first steps and first years of HTP, and in the second and third steps, health insurance organizations were affected because of not raising insurance revenues. This led to an imbalance in revenue and expenditure and budget deficit and also delays in reimbursement of invoices of health care providers, which sometimes reaches one year. [Member of Parliament]

Therefore, it has affected the funding and liquidity cycle in the health system, and most stakeholders including healthcare providers, pharmaceutical companies (both manufacturers and distributors), and contractor companies which had a contract with Medical Sciences Universities (MSU) and hospitals.

Another reason for the unpredictability of financing resources is dependence on public revenue funding (eg, public taxes and other sources of income), which is not earmarked, and its allocation path and spending are not specified from the beginning. In these cases, the existence of unpredictable circumstances can change the direction of credits and then allocate to new requirements. It is also likely that resource allocation may not be expanded where it has been allocated by the legislature, or related revenue is not realized.

According to the participants, in this period, challenges of the economic situation of the country, increasing national donor flows, and moving to establish health charity institutions to absorb some revenues is necessary. Taxes on fossil fuels, as well as harmful products such as tobacco, are one such option mentioned by some interviewees in order to increase revenues. Participants believed that it increases the resources governments can spend on HTP and the overall population's health.

\section{Health Services Purchasing and Resource Allocation}

Public resources are allocated by the PBO in Iran. This organization is responsible for governmental financial resource management. In the budget execution, BPO takes some considerations, which lead to a delay in budget allocation. According to the participants and findings from the literature review, delays in the financing cycle are divided into two sections, predictable and unpredictable. A part of the delays is entirely predictable and even becoming accustomed to the funding and allocation of resources.

We are waiting every year for such delays. With Implementing HTP we hoped to receive reimbursements in appropriate times. But unfortunately, especially in the two last year, we deal with this problem in our hospitals. [Hospital manager]

According to the participants, unpredictable delays are mainly due to the lack of funds through the lack of realization of revenue sources and also lack of realization of projected headings for collection of revenues at a macro level. For example, according to the Iranian economic situation, one of the main sources of funding is oil revenues, which are usually unstable and affected by several unpredictable factors such as economic sanctions, national and international political conditions, and unexpected events in some parts of the world, and the existence of conflicts and civil wars in oil-producing regions.

All of the HTP money and most of the funds was allocated by $\mathrm{PBO}$ to IHIO. Public service providers are usually funded through health insurance funds. Therefore, any delays in reimbursing the public service providers' reimbursements can make it difficult to provide a service in this sector. As a solution, the parliament approved to transfer IHIO from the Ministry of Cooperatives, Labor, and Social Welfare to MoHME. Some experts stated that this policy was pursued by MoHME, which aimed to be responsible for the HTP funding source. While after 18 months of that approval, it showed that this policy could not resolve, alleviate, or overcome HTP funding challenges.

We found that all HTP resources depend on Budgetary and Planning Organization Decision. Whenever this organization does not allocate necessary resources to MoHME, the interventions such as transferring insurance organization under the supervision of MoHME will not solve the current financial challenges. [Senior provincial health manager]

According to the participants, it is also likely that resource allocation may not be expended appropriately where it has been allocated by the legislature, or related revenue is not 
realized. It can be noted that $10 \%$ of the total net of implementation of targeted subsidy law and also $1 \%$ of the VAT, which was supposed to be allocated to the health system, unfortunately were not realized except in the beginning implementation phase of HTP.

It is expected that the situation is gradually returning to the situation before the HTP implementation. Because of financial challenges and not the appropriate allocation of financial resources to this plan, a former minister of health resigned and quit governments' body. [Health planner]

The HTP spent more money on health, and despite the highest spending, did not reach measures of health system performance in critical areas of quality, efficiency, access to care, and equity. MoHME did not efficiently use resources, and inefficiencies account for a major resource being wasted.

Despite the achievements of the Health Transformation Plan, lack of consistency and a sound economic logic hindered the realization of the ultimate goals of the plan and, over time, some of its positive outcomes, gained by expensing of huge resources, have started to regress, which requires further review. [Health researcher]

\section{Provider Payment Mechanism}

Recently, the fee for services became a widespread mechanism through implementing the pay for performance method and updating the Relative Value Units (RVUs). This resulted in two main challenges: fast-rising health system expenditure and inequity in payments. In spite of the enhancement of payments and creating relative satisfaction, some groups of health practitioners and employees, such as nurses and some medical specialists, are dissatisfied. They claim that these changes in payment are unfair and enlarged the gaps among medical specialists, and between medical specialists and other employees and health-care providers.

Creating reform in the payment system, which is full of structural conflicts of interest is not an easy feat. The Health Transformation Plan is like a train that doesn't stop in any station, but we must attempt to make costs more reasonable. Payments should be reasonable based on actual prices of health care services. Reform in the payment system is not possible without a critique of the past.

[MoHME advisor]

Although this reform had significant outcomes but lack of integration in the implementation and lack of proper economic logic has caused many challenges for health insurance funds such as delay in reimbursements, the waste of resources in the service delivery system or transferring burden of out-patient care to the hospitals. [Doc 8, newsletter, SalamatNews, in Persian, 2017]] $]^{32}$

\section{Pooling Management}

Resources are limited, and the government has the limit fiscal space to govern and administrates many obligations, functions, and sectors. When financing policymakers allocate revenue to health, it means a reduction in the share of other areas, including agriculture, education, and social affairs. Under such circumstances, pressure from different areas on the national resources planning board intensifies. This is very critical and sensible when the GDP growth is low or negative; the share of the total health expenditure (THE) as a percent of GDP goes up. The more the gap between growth in health expenditure and economic growth, the greater the pressure will be on the government for healthcare financing.

Some participants believed that Iran's health financing is fragmented, and HTP intensified this fragmentation. They implied that the financial resources of HTP should be collected and pooled in the health insurance organization. The health insurance organization is responsible for the management of health financial resources and services purchasing. MoHME needs to care more about the prescribing and utilization of services.

Resource management should be done by insurance organizations and not by MoHME. The role of MoHME is supervision and stewardship and not collecting or pooling of the financial resources. [Senior health insurance director]

Participants mentioned that lack of an accurate and transparent process for financing the long-term plans of government and also deviation in the HTP are the main reasons for the disagreement between the MoHME and PBO in the pooling of resources. They also suggested that health system policymakers are required to consider the revenue growth, which depends on not only the rate and base of the tax but also on the priority setting of total country objectives, eg, whether a country is willing to give up other purposes to increase health sector funds. Therefore, it seems that educating some fundamental principles about resource allocation and pooling is necessary for Iran health policymakers.

As recognized in one of the reviewed documents, the International Labor Organization (ILO) emphasizes that 
the instability of resources in the field of insurance schemes effectively makes theseschemes a factor in the dissatisfaction of stakeholders.

There are 18 insurance funds in our country, only one or two of which are able to stand on their own two feet. The rest of the funds have either overtaken their resources or are on the verge of bankruptcy, so the framework emphasized by the International Labor Organization has not been taken into account by the Ministry of Health. [Doc 14, newsletter, Tasnim News Agency, in Persian, 2015] ${ }^{51}$

\section{Discussion}

Our paper explores Iran's HTP in the light of financing function and its dimensions through experts' opinions and a literature review. Our study implies that revenue sources for health financing should meet some criteria. Some studies suggest that the suitability of revenues and sources of funding are controversial issues. ${ }^{16,33}$ Our findings also showed these two important issues are the challenging factors for implementing the HTP in the country. Moreover, other studies indicate ways of revenue collection for the funding of health that should be assessed in terms of efficiency, equity, revenue-raising potential, revenue administration, and sustainability. ${ }^{34-37}$

The International Monetary Fund (IMF) and the World Bank also suggest some criteria for the assessment of revenue sources. They mentioned that all revenue sources should raise a significant amount of revenue, be relatively stable, and be likely to rise over time. ${ }^{38}$ On the other hand, the revenue source should be simple to administer, and it has to be politically acceptable. Definitely, smarter fiscal policies have a key role in reducing inequality by striking the right balance between growth, debt sustainability, and social protection.

It is important to consider the fiscal capacity and implementation of financing strategies. Fiscal capacity is contextual, and the results of the selected financing strategy depend on the economic structure and the government's administrative capacity. It appears that revenue-raising has some requirements, such as a recording system, a system of revenue gathering from source, an accounting system and a system for organizing administrative agencies; ${ }^{39}$ according to our study there is no such system for performing these crucial functions.

It seems that VAT as a revenue source of HTP meets these criteria, but there is a little doubt that the subsidy targeting revenue meets them. Based on subsidy targeting law, Iran should remove the energy carriers' subsidy and raise the internal price of energy carriers to international prices (Fee On Boat price). ${ }^{40}$ But due to socioeconomic considerations, the government did not remove subsidy and did not increase energy carriers' prices in recent years.

Although trade-offs among these criteria in some conditions are inevitable, it is necessary to pay attention to the institutional and macroeconomic constraints that may preclude the country from applying the most efficient and equitable revenue-raising ways. ${ }^{41,42}$

Based on our results, delay in both reimbursements and budget allocation is another challenge that HTP encountered. A review of evidence shows delaying compensation and payment for near to one year. ${ }^{15}$ First, one of the reasons for delaying in reimbursement, allocating, and payment is that additional expenditure had not been predicted appropriately, and additional expenditure was more than the estimated revenue. ${ }^{43}$ Second, the shrinking of fiscal space due to the oil revenue decreasing led to delays in the budget allocation and HTP revenue raising. Third, health expenditure is not like infrastructure expenditure, which happens once and ends. It does not only continue but also grows over time, and the revenue must be grown as well. ${ }^{38}$

Fragmentation in financing management and pooling is the other challenge that we found in our research. Based on our results in HTP, MoHME manages the revenues and resources; meanwhile, most HTP expenditure is paid for by the health insurance organization. MoHME plays a purchaser role, and this leads to more fragmentation and expenditure increases. However, in most low- and middle-income countries, due to the lack of limited private arrangements and multiple public sectors, system fragmentation seems to be normal rather than an exception. ${ }^{38}$

Equity in payments is the other main challenge that HTP encounters. Based on our findings, the HTP not only does not improve the personal payments equity but also exacerbates it and increases the gap between them. However, this is the feeling of our respondents, and other research confirmed that. ${ }^{16}$

Establishing a Family Physician Plan and referral system and the use of clinical practice guidelines is a way to avoid unnecessary utilization of health-care services. ${ }^{44}$ Training of executives, especially hospital managers and presidents, should have begun earlier and be done more effectively. $^{45}$

Like other plans, HTP has weaknesses along with its benefits, which must be addressed with proper measures. 
Given the findings of this study, almost all interviewees stated the government does not have more fiscal spaces to allocate more resources to health. Therefore, cost analysis and cost control strategies in both of the cost elements (price and quantity), such as control overuse, developing referral systems and guideline and rearrangement of the payment system, need to be taken into consideration. Anticipated economic circumstances for this and future years (projected real GDP growth for 2019 by IMF $-6 \%$ and inflation rate equal to $37.2 \%$ ) do not produce a clear picture of healthcare financing. However, the future path can be improved with a more logical approach to policymaking by using the lessons learned. Improving the efficiency of the health system and cost control are logical ways to progress from this point and to preserve and sustain the transformation plan's achievements. Waste and inefficiencies account for a significant source of increases in health expenditure. Studies show that over $20-40 \%$ of health-care expenditure is due to inefficiency. ${ }^{46,47}$

In order to ensure the successful continuation of the implantation of HTP in the long run, we need robust evaluation and analysis mechanisms to evaluate the plan and its effects to generate evidence for reconstruction or modification. ${ }^{15,48-50}$ HTP should be promptly analyzed whereby parts of the plan with higher achievement/cost or with more critical services are revised and maintained. In contrast, parts of the plan that have caused unreasonably high costs for the system are eliminated and replaced with better alternatives. In other words, the program is adapted to the country's current situation and to the real public needs.

\section{Conclusion}

HTP has pitfalls in all functions of financing. Sustainability in revenue, equity in payment, defining proper indices for allocation, unifying, and pooling of resources are the main challenges of HTP at the financial level. Resolving all of the above-mentioned problems without an insurance mechanism is a significant strategic mistake. It is necessary to involve health insurance organizations more than in the past and to manage overuse and reimbursement. Finally, it can be assumed that the adoption and implementation of evidence-informed policies and future-based strategies can prevent further potentially inappropriate consequences.

\section{Abbreviations}

HTP, Health Transformation Plan; FGD, focus group discussion; GDP, gross domestic product; MoHME, Ministry of
Health and Medical Education; MSU, Medical Sciences Universities; UHC, universal health coverage; PHC, primary health care; OOP, out of pocket payment; VAT, value-added tax; PBO, Planning and Budgeting Organization; SSO, Social Security Organization; IHIO, Iran Health Insurance Organization; AFMSIO, Armed Forces Medical Services Insurance Organization; IKRF, Imam Khomeini Relief Foundation Health Insurance; FFS, fee for services; IMF, International Monetary Fund.

\section{Ethics Approval and Consent Statement}

This study as part of a large study was approved by the Research Council of NIHR including ethical consideration (Grant No: 241/M/9395). All ethical considerations were considered, reviewed, and decided upon by the Research Council of NIHR that would approve and grant permission to conduct the study. Before starting the interviews, the study's aim and objectives were explained in detail to the interviewees. Following the ethical protocol, due to the nature of the study and the selected method for data collection, we acquired verbal consent from the participants that was acceptable by the Research Council of NIHR. However, consent was audio recorded, where we guaranteed interviewees of their privacy, confidentiality, and anonymity of any information they may provide. We assured the participants that participating in the research is a voluntary choice, and they have the right to opt out of the interview when they want.

\section{Acknowledgments}

The authors would like to thank all interviewees who participated in this research.

\section{Author Contributions}

All authors made substantial contributions to conception and design of the study, acquisition of data, analysis and interpretation of data; took part in drafting the article or revising it critically for important intellectual content; gave final approval of the version to be published; and agree to be accountable for all aspects of the work in ensuring that questions related to the accuracy or integrity of any part of the work are appropriately investigated and resolved.

\section{Disclosure}

All the authors declare that they do not have any competing interests regarding the publication of this paper. 


\section{References}

1. The World Health Report. Health Systems Financing: The Path to Universal Coverage. World health organization (WHO); 2010.

2. World Health Organization. The World Health Report 2000: Health Systems: Improving Performance. World Health Organization; 2000.

3. Marton J, Sung J, Honore P. Does more public health spending buy better health? Health Serv Res Manag Epidemiol. 2015;2:2333392815580750.

4. World Health Organization. World Health Report, 2010: Health Systems Financing the Path to Universal Coverage. 2010.

5. Kutzin J. Health financing for universal coverage and health system performance: concepts and implications for policy. Bull World Health Organ. 2013;91(8):602-611. doi:10.2471/BLT.12.113985

6. Akca N, Sonmez S, Yilmaz A. Determinants of health expenditure in OECD countries: a decision tree model. Pak J Med Sci. 2017;33 (6):1490-1494. doi:10.12669/pjms.336.13300

7. Rezaei S, Fallah R, Karyani AK, Daroudi R, Zandiyan H, Hajizadeh M. Determinants of healthcare expenditures in Iran: evidence from a time series analysis. Med J Islam Repub Iran. 2016;30:313.

8. Dieleman JL, Sadat N, Chang AY. Trends in future health financing and coverage: future health spending and universal health coverage in 188 countries, 2016-40. Lancet. 2018;391(10132):1783-1798. doi:10. 1016/S0140-6736(18)30697-4

9. Frenk J, Gómez-Dantés O, Knaul FM. The democratization of health in Mexico: financial innovations for universal coverage. Bull World Health Organ. 2009;87(7):542-548. doi:10.2471/BLT.08.053199

10. Takian A, Doshmangir L, Rashidian A. Implementing family physician programme in rural Iran: exploring the role of an existing primary health care network. Fam Pract. 2013;30(5):551-559. doi:10.1093/fampra/cmt025

11. Doshmangir L, Rashidian A, Jafari M, Takian A, Ravaghi H. Opening the Black Box: The Experiences and Lessons From the Public Hospitals Autonomy Policy in Iran. Arch Iran Med. 2015;18 (7):416-424

12. Doshmangir L, Moshiri E, Mostafavi H, et al. Policy analysis of the Iranian health transformation plan in primary healthcare. $B M C$ Health Serv Res. 2019;19(1):670. doi:10.1186/s12913-019-4505-3

13. Doshmangir L, Bazyar M, Majdzadeh R, et al. So near, so far: four decades of health policy reforms in iran, achievements and challenges. Arch Iran Med. 2019;22(10):592-605.

14. Doshmangir L, Bazyar M, Najafi B, et al. Health financing consequences of implementing health transformation plan in iran: achievements and challenges. Int $J$ Health Policy Manag. 2019;8 (6):384-386. doi:10.15171/ijhpm.2019.18

15. Olyaeemanesh A, Behzadifar M, Mousavinejhad N, et al. Iran's health system transformation plan: a SWOT analysis. Med J Islam Repub Iran. 2018;32(1):39. doi:10.14196/mjiri.32.39

16. Moradi-Lakeh M, Vosoogh-Moghaddam A. Health sector evolution plan in Iran; equity and sustainability concerns. Int $J$ Health Policy Manag. 2015;4(10):637. doi:10.15171/ijhpm.2015.160

17. Mehrolhassani M, Najafi B, Yazdi Feyzabadi V, et al. Total health expenditures and proportion of out-of-pocket payments in Iranian provinces; 2008-2014. Iran J Epidemiol. 2017;12(5Special Issue):1-12.

18. Yazdi Feyzabadi V, Bahrampour M, Rashidian A, et al. Incidence and intensity of catastrophic health expenditures in Iranian provinces; 2008-2014. Iran J Epidemiol. 2017;12:40-54.

19. Abdi Z, Hsu J, Ahmadnezhad E, Majdzadeh R, Harirchi I. An analysis of financial protection before and after the Iranian health transformation plan. East Mediterr Health J. 2019;25.

20. Moradi T, Naghdi S, Brown H, et al. Decomposing inequality in financial protection situation in Iran after implementing the health reform plan: what does the evidence show based on national survey of households' budget? Int J Health Plan Manag. 2018;33 (3):652-661. doi:10.1002/hpm.2517

21. Davari M, Haycox A, Walley T. Health care financing in Iran; is privatization a good solution? Iran J Public Health. 2012;41(7):14-23.
22. Bazyar M, Rashidian A, Alipouri Sakha M, et al. Combining health insurance funds in a fragmented context: what kind of challenges should be considered? BMC Health Serv Res. 2020;20(1):26. doi:10.1186/s12913-019-4858-7

23. Bazyar M, Rashidian A, Sakha MA, et al. Stakeholders analysis of merging social health insurance funds in Iran: what kind of interests they may gain or lose? Int J Health Plann Manage. 2019;34 (1):157-176. doi:10.1002/hpm.2605

24. Davari M, Haycox A, Walley T. The Iranian health insurance system; past experiences, present challenges and future strategies. Iran J Public Health. 2012;41(9): 1.

25. Zare H, Trujillo AJ, Driessen J, et al. Health inequalities and development plans in Iran; an analysis of the past three decades (1984-2010). Int J Equity Health. 2014;13(1):42. doi:10.1186/1475-9276-13-42

26. Parliament I. National health insurance act. J Med Serv Insurance Organ. 1994; 7:68-71.

27. Bazyar M, Rashidian A, Kane S, et al. Policy options to reduce fragmentation in the pooling of health insurance funds in Iran. Int $J$ Health Policy Manag. 2016;5(4):253. doi:10.15171/ijhpm.2016.12

28. Maxwell JA. Designing a qualitative study. SAGE Handb Appl Social Res Methods. 2008;2:214-253.

29. Sapsford R, Jupp V. Data Collection and Analysis. Sage; 1996.

30. Guest G, MacQueen KM, Namey EE. Applied Thematic Analysis. Sage Publications; 2011.

31. Vaismoradi M, Jones J, Turunen H, Snelgrove S. Theme Development in Qualitative Content Analysis and Thematic Analysis. 2016.

32. Head of the Ministry of Health. The Health Transformation Plan had no economic logic. SalamatNews. Available from: http://www.sala matnews.com/news $/ 263290 / \% \mathrm{D} 8 \% \mathrm{~B} 7 \% \mathrm{D} 8 \% \mathrm{~B} 1 \% \mathrm{D} 8 \% \mathrm{AD}-\% \mathrm{D} 8 \%$ AA $\%$ D8\%AD\%D9\%88\%D9\%84-\%D8\%B3\%D9\%84\%D8\%A7\% D9\%85\%D8\%AA-\%D9\%85\%D9\%86\%D8\%B7\%D9\%82-\%D8\% A7\%D9\%82\%D8\%AA \%D8\%B5\%D8\%A7\%D8\%AF\%DB\%8C-\% D9\%86\%D8\%AF\%D8\%A7\%D8\%B4\%D8\%AA. Accessed July 2, 2020. Persian.

33. Ferdosi M, Kabiri S, Keyvanara M, Yarmohammadian MH. Challenges of iran health transformation plan about inpatients payment: viewpoint of experts. Health Scope. 2017;6(3).

34. Schieber GJ. Innovations in Health Care Financing: Proceedings of a World Bank Conference, 10-11 March 1997. The World Bank; 1997.

35. Tanzi MV. Tax Policy for Emerging Markets-Developing Countries. International Monetary Fund; 2000.

36. World Health Organization. Mobilization of Domestic Resources for Health. WHO; 2002.

37. Dodd R, Hinshelwood E. Poverty Reduction Strategy Papers-Their Significance for Health. Geneva, Switzerland: World Health Organization; 2002.

38. Gottret P, Schieber G. Health Financing Revisited: A Practitioner's Guide. The World Bank; 2006.

39. Roberts M, Hsiao W, Berman P, Reich M. Getting Health Reform Right: A Guide to Improving Performance and Equity. Oxford university press; 2003.

40. Iran, I.P.o., Subsidy Targeting Law, I.P.o. Iran, Editor. 2009. Islamic Parliment of Iran: Tehran, Iran.

41. IMF IMF, WB WB. Financing the development agenda; 2005 [cited July 18, 2019]. Available from: http://documents.worldbank.org/ curated/en/634821468320670332/pdf/32385.pdf.

42. Ferreira FH, Walton M. World Development Report 2006: Equity and Development. World Bank Publications; 2005.

43. World Health Organization. Public Spending on Health: A Closer Look at Global Trends. WHO; 2018.

44. Hasanpoor E, Janati A, Arab-Zozani M, et al. Using the evidence-based medicine and evidence-based management to minimize overuse and maximize quality in healthcare: a hybrid perspective. BMJ Evid Based Med. 2020;25(1):3-5. doi:10.1136/ bmjebm-2018-110957 
45. Arab-Zozani M, Moynihan RN, Pezeshki MZ. Shared decision making: how can it be helpful in reducing medical overuse due to medical misinformation mess? J Eval Clin Pract. 2020;26(2):602-603. doi:10.1111/jep. 13358

46. OECD. Tackling Wasteful Spending in Health Care. 2017.

47. World Health Organization. World Healh Report (The): Health Systems Financing: The Path to Universal Coverage (Arabic). WHO; 2010.

48. Buse K. Addressing the theoretical, practical and ethical challenges inherent in prospective health policy analysis. Health Policy Plan. 2008;23(5):351-360. doi:10.1093/heapol/czn026
49. Coveney J. Analyzing public health policy: three approaches. Health Promot Pract. 2010;11(4):515-521. doi:10.1177/1524839908318831

50. Hercot D, Meessen B, Ridde V, et al. Removing user fees for health services in low-income countries: a multi-country review framework for assessing the process of policy change. Health Policy Plan. 2011;26(suppl_2):ii5-ii15. doi:10.1093/heapol/czr063

51. Tasnim News Agency. Challenges and 13 Weaknesses of Health Transformation Plan + Suggestions. Tasnim News Agency. 2016 March 6; 19:09. Available from: https://tn.ai/1019867. Accessed July 2, 2020. Persian.

\section{Publish your work in this journal}

ClinicoEconomics and Outcomes Research is an international, peerreviewed open-access journal focusing on Health Technology Assessment, Pharmacoeconomics and Outcomes Research in the areas of diagnosis, medical devices, and clinical, surgical and pharmacological intervention. The economic impact of health policy and health systems organization also constitute important areas of coverage. The manuscript management system is completely online and includes a very quick and fair peer-review system, which is all easy to use. Visit http://www.dovepress.com/testimonials.php to read real quotes from published authors. 